\title{
Sentidos atribuídos à oficina de teatro em centros socioeducativos
}

The senses attributed to the theater workshop at socioeducational centers

http://dx.doi.org/10.5007/2178-4582.2014v48n1p35

Fernanda Roberta Lemos Silva

Universidade Estadual de Campinas, Campinas/SP, Brasil

\begin{abstract}
O presente artigo é parte integrante da pesquisa "O trabalho do arte-educador de Teatro na Fundação Casa". Neste recorte do trabalho apresento as narrativas coletadas durante a pesquisa de campo realizada com jovens egressos e arte-educadores (teatro), retratando as contradições entre a proposta pedagógica da Fundação Casa no que se refere à proposta de Arte e Cultura e o desenvolvimento prático das oficinas de teatro em Centros Socioeducativos. Através da narrativa dos sujeitos entrevistados, a pesquisa teve como objetivo analisar aspectos do trabalho do arte-educador nesse espaço de cumprimento de medida socioeducativa, e os enfrentamentos do trabalho com arte-educação nesse contexto.
\end{abstract}

Palavras-chave: Arte-educação - Oficina de Teatro - Ressocialização.
The present paper is part of the research entitled "The work of theater art educator at the House Foundation". In this clipping from the work, I present the narratives collected during fieldwork carried out with youngsters egressed of the institution as well as with the theater art educators, portraying the contradictions that exist between the House Foundation's pedagogical proposal regarding to Arts and Culture and the development of practical theater workshops at such socioeducational centers. Through the narrative of the interviewees, the research aimed to analyze aspects of the work of the theater art educator in this space of implementation of socioeducational measures and the clashes of the art education work in this context.

Keywords: Art education - Theatre Workshop - Resocialization.

\section{Introdução}

A Fundação Casa (Centro de Atendimento Socioeducativo ao Adolescente), instituição que inspirou este trabalho, presta assistência a jovens de 12 a 21 anos em todo o Estado de São Paulo SP, por meio de uma proposta de ressocialização. Um dos eixos de trabalho com os adolescentes é proporcionar autonomia para que sejam protagonistas de sua história e não reincidam na prática de atos infracionais.

Concomitante a um amplo processo de mudança, e de acordo com a Lei $\mathrm{N}^{\mathrm{o}} 12.469$ de 22 de dezembro de 2006, também houve a mudança de nomenclatura da então FEBEM (Fundação de Atendimento ao Bem-Estar do Menor) para Fundação Casa (Centro de Atendimento Socioeducativo ao Adolescente).

As ações pedagógicas da Fundação Casa não se restringem ao ensino formal e estão divididas em três segmentos: Educação Profissional; Arte e Cultura; e Esportes. De acordo com Costa (2006), deve haver o trabalho de socioeducação no Brasil para que os jovens encontrem possibilidades de con- 
viver em sociedade sem quebrar as regras de convivência, e para que estejam inseridos como seres participantes dessa mesma sociedade.

Porque o jovem que cometeu ato infracional, na maioria dos casos, não dá certo na escola, no trabalho e na vida, não pela falta de encaminhamentos para a escola ou oportunidades de profissionalização, mas porque lhe faltou acesso a uma educação mais ampla, que lhe possibilitasse aprender a ser e aprender a conviver (apud SOUZA, 2011, p.62).

A Gerência de Arte e Cultura (GAC), pertencente à Superintendência Pedagógica, é a área responsável pela política cultural da Fundação Casa, bem como pelas diretrizes de ação cultural em relação aos adolescentes que cumprem medidas socioeducativas.

De acordo com o ECA - Estatuto da Criança e do Adolescente (BRASIL, 2002), os instrumentais norteadores do trabalho com adolescentes em cumprimento de medidas socioeducativas, e que garantem o acesso à arte durante $\mathrm{o}$ período de internação propõem que:

Art.124 - São direitos do adolescente privado de liberdade entre outros os seguintes:

XII - realizar atividades culturais, esportivas e de lazer.

XIII- ter acesso aos meios de comunicação social.

Além disso, o Eixo Esporte, Cultura e Lazer previsto no SINASE - Sistema Nacional de Atendimento Socioeducativo propõe:

[...] 2- Propiciar o acesso a programações culturais, teatro, literatura, dança, música, artes, constituindo espaços de oportunização, da vivência de diferentes atividades culturais e artísticas, e também de favorecimento a qualificação artística respeitando as aptidões dos adolescentes.

[...]5- Assegurar no atendimento socioeducativo espaço a diferentes manifestações culturais dos adolescentes.

[...] 8- Garantir que as atividades esportivas de lazer e culturais previstas no projeto pedagógico sejam efetivamente realizadas, assegurando assim que os espaços físicos destinados às práticas esportivas, de lazer e cultura sejam utilizadas pelos adolescentes. (BRASIL, 2006, p.60)

De acordo com o site da Fundação Casa, consultado em 2013:

[...] os adolescentes atendidos são oriundos, em sua maioria das camadas mais pobres e estão cada vez mais sujeitos a um 
processo de exclusão social. Por isso, a cultura deve ser compreendida nesse contexto de exclusão, no qual o acesso dos cidadãos às práticas artístico-culturais não é igualitário, mas muitas vezes um privilégio das camadas sociais mais abastadas (FUNDAÇÃO CASA, s/d).

Segundo Penna (2011), "é preciso pensar como superar as barreiras que separam arte e jovens de classes menos favorecidas". Assim, percebe-se que as atividades culturais oferecidas no centro socioeducativo podem ser o primeiro contato do adolescente com uma "vivência artística". Entretanto, o jovem não se sente capaz de participar de uma oficina de circo, dança ou teatro, pois ele se auto-atribui um rótulo de "infrator" e tem dificuldade de se reconhecer como alguém que canta, dança ou interpreta. Para eles, um jovem infrator rouba, mata e vende droga. Isto porque, conforme Carvalho:

\begin{abstract}
As desigualdades sociais constituem por si só, um grave problema por ensejar a desintegração e a vulnerabilidade social, além de impedir que uma parte expressiva de nossa população possa usufruir dos direitos mais elementares para a sobrevivência do ser humano: subsistência, saúde, habitação, segurança, educação e lazer. O impacto dessa realidade afeta de forma mais dramática aqueles que, como as crianças e os adolescentes ainda se encontram em processo de formação (CARVALHO, 2008, p.13).
\end{abstract}

De acordo com a Fundação Casa, a proposta do oferecimento de oficinas culturais para adolescentes privados de liberdade é "promover atividades conectadas às várias manifestações culturais nacionais e internacionais, às quais os adolescentes não tiveram acesso". Porém, durante a minha experiência como arte-educadora nos Centros pude perceber que muitas situações, discursos e regras promovidas pelo "sistema disciplinar" dos centros socioeducativos afirmam a compreensão de que a arte é lazer, luxo, regalia para os adolescentes e que se trata de uma atividade para entretenimento, utilizada para distrair os internos e livrá-los do tempo ocioso.

Cabe ressaltar que a discussão apresentada neste artigo descreve como se dá a compreensão pedagógica no oferecimento de oficinas culturais com jovens em situação de risco, que possuem em suas trajetórias de vida marcas da desigualdade social, influência do tráfico de drogas e da violência, onde as chances de "ressocialização" estão distantes da realidade em que vivem.

\title{
Fundamentação teórica
}

Para Coelho (1999) "arte-educação é a ciência do ensino da arte". De acordo com este autor: 
É sob este aspecto educacional que arte-educação tem o potencial de tornar-se um instrumento de ação cultural ou de mudanças sociais pelo desenvolvimento da percepção visual da imaginação criativa, do desenvolvimento da flexibilidade na resolução criativa de problemas de todo tipo e da formação de valores estéticos que se refletem tanto no entorno humano e urbano quanto nas obras de arte (COELHO, 1999, p.56).

Para Duarte Junior (1994), a arte-educação não significa um treino para alguém se tornar um artista e pode ser vista como uma forma mais ampla de se abordar o fenômeno educacional. Neste caso, ela deixa de ser apenas uma transmissão simbólica de conhecimentos e se transforma em um processo formativo humano que envolve a criação de um sentido para a vida e que faz emergir os nossos sentimentos peculiares.

\begin{abstract}
Na experiência estética o cotidiano é colocado entre parênteses e suspenso suas regras são abolidas. Por um momento princípio do prazer coloca diante de nós a sua criação que nos envolve carinhosamente. $\mathrm{O}$ mundo real desfez-se do seu ventre estéril surge uma nova realidade com que nos embriagamos misticamente. Esta é a experiência estética: uma suspensão provisória da causalidade do mundo, das relações conceituais que nossa língua forja. Ela se dá com a percepção global de universo do qual fazemos parte e com o qual estamos em relação (DUARTE JUNIOR, 1988, p.91).
\end{abstract}

Foram adotados como sujeitos desta pesquisa três arte-educadores de teatro. Dos três arte-educadores entrevistados dois ainda atuam como professores de teatro na Fundação Casa. As entrevistas semiestruturadas com os adolescentes foram gravadas em áudio, após a passagem pelos centros; e, com os arte-educadores fora do espaço físico da Fundação Casa.

Para Antônio Joaquim Severino,

[...] as entrevistas estruturadas são aquelas que são direcionadas e previamente estabelecidas, com determinada articulação interna. Aproxima-se mais do questionário, embora sem a impessoalidade deste. Com questões bem diretivas, obtém o universo de sujeitos, respostas também mais facilmente categorizadas, sendo assim, muito útil para o desenvolvimento de levantamentos sociais (SEVERINO, 2007 p.125).

Segundo GODOI (2006), é na década de 1930 que a entrevista começa a ser utilizada amplamente pelas ciências sociais nas tarefas de investigação. A pesquisa qualitativa lida com interpretações das realidades sociais. Segundo Bauer (2007), na pesquisa social, estamos interessados na maneira como as pessoas espontaneamente se expressam e falam sobre o que é importante para 
elas, e em como pensam sobre suas ações e as dos outros. Considera, ainda, que a entrevista é um processo social em que as palavras são o principal meio de troca.

Bauer afirma que a entrevista qualitativa fornece os dados básicos para o desenvolvimento e a compreensão das relações entre atores sociais e sua situação. O objetivo da pesquisa qualitativa é uma "compreensão detalhada das crenças, atitudes, valores e motivações em relação aos comportamentos das pessoas em contextos sociais específicos" (Ibid.,p.73).

Os referenciais teóricos utilizados neste trabalho se baseiam no trabalho dos autores Lopes (1989), Spolin (2001), Duarte Junior (1994), Desgranges (2009) Yamamoto (2010), Bauer (2007), Godoi (2006), Silva, Neto e Moura (2011) e Graciani (2011). No que se refere às discussões sobre arte-educação, foram utilizados também os referenciais de Joana Lopes (1989), Viola Spolin (2001) e Duarte Junior (1994).

Lopes (1989, p.106) propõe como método de trabalho "um conjunto de ações provocadoras da criatividade e expressividade crítica tendo como resposta um atuante consciente de seus estereótipos de expressão e limitações impostas à sua criatividade de homem artista". Para a autora, a arte-educação tem o papel de incentivar e oferecer princípios de trabalho prático que levam o aluno da oficina, ou "espectador", a um processo crítico.

Nessa direção, Duarte Junior acredita que na "verdadeira arte-educação o que se busca é despertar a consciência dos indivíduos para o valor que a arte possui em si própria." (1994, p.146), e explica que:

Através da arte o indivíduo pode expressar aquilo que o inquieta e o preocupa. Por ela este pode elaborar sentimentos, que haja uma evolução mais integra entre conhecimento simbólico e seu próprio "eu" a arte coloca-o frente a frente com a questão da criação: a criação de um sentido pessoal que oriente sua ação no mundo (DUARTE JUNIOR, 1994, p.73).

A proposta de Spolin (2009) sugere que o processo de atuação no teatro deve ser baseado na participação em jogos. Através do envolvimento do aluno com as relações presentes no jogo, ele desenvolve a liberdade pessoal dentro das regras estabelecidas, criando técnicas e habilidades necessárias para o jogo. Desse modo, interioriza a espontaneidade e se transforma em um jogador criativo.

Os jogos são sociais, baseados em problemas a serem solucionados. O problema a ser solucionado é o objeto do jogo. As regras do jogo incluem a estrutura (onde, quem, o que) e o objeto (foco) mais o acordo de grupo (SPOLIN, 2009, p.43). 
Do ponto de vista da Pedagogia do Teatro, os referenciais teóricos escolhidos para dialogar com este trabalho foram os trabalhos dos autores Desgranges (2010) e Yamamoto (2009). Desgranges incentiva, em sua obra, compreender a ação educativa proposta pela experiência teatral como uma provocação dialógica.

\footnotetext{
$\mathrm{O}$ acesso ao teatro, porém não se resume a possibilitar a ida às salas (ou a levar espetáculos itinerantes a regiões menos favorecidas). Formar espectadores não se restringe a apoiar e estimular a frequentação, é preciso capacitar o espectador para um rico e intenso dialogo com a obra, criando assim, o desejo pela experiência artística. (DESGRANGES, 2010, p.29).
}

Yamamoto inspira este trabalho ao apresentar trajetórias teatrais realizadas com adolescentes internos no internato de Pirituba (Fundação Casa). Segundo a autora, a vivência teatral:

Pode possibilitar a construção de ideias por parte desses meninos que, possivelmente pela primeira vez, apoderando-se de sua criatividade, reinventando e realmente se observando, tentaram se compreender em relação ao que chamam de sociedade valendo-se do caráter fictício que só o teatro traz em si, sem armas, sem violência, apenas como seres humanos se relacionando uns com os outros (YAMAMOTO, 2009, p.33).

No âmbito da Pedagogia Social, de acordo com GRACIANI (2011), abordou-se a relação do educador com o espaço de trabalho, considerando as necessidades psicológicas e os conflitos dos adolescentes privados de liberdade. Estes aspectos foram observados neste trabalho no que se refere à formação e perfil do educador que atua com jovens que cumprem medida socioeducativa.

Além das competências técnicas, relacionadas à linguagem dos educadores que ministram as oficinas culturais são imprescindíveis, ao educador que atua com o público alvo dessa pesquisa, posicionamentos pessoais e sociais para o enfrentamento de situações conflituosas.

\section{Oficinas culturais para jovens privados de liberdade no âmbito dos Cen- tros socioeducativos}

No que se refere aos conceitos e diretrizes, a proposta pedagógica de Arte Cultura da Fundação Casa propõe que as ações educativas com os adolescentes tenham uma intencionalidade. Ao propor qualquer atividade, pressupõe-se que os objetivos sejam bem definidos. 
As oficinas culturais oferecidas pelos Centros contemplam as áreas Artes Cênicas (teatro, jogos dramáticos e circo); Artes Visuais (vídeo, oficina de imagem, histórias em quadrinhos, artes plásticas); Cultura Urbana (dança de rua, grafite, rap, DJ); Artes da palavra (vídeo, jornal, literatura e rádio); Artes do corpo (capoeira e danças em geral); e Música (canto coral, cavaquinho, violão, percussão).

Desse modo, as atividades de arte e cultura são divididas nas seguintes ações: oficinas culturais (que ocorrem semanalmente), workshops, palestras e mostras. As oficinas oferecidas devem contemplar $100 \%$ dos adolescentes dos Centros, oferecendo, no mínimo, uma oficina por jovem, de maneira que cada oficina tenha o número ideal de 10 adolescentes (no máximo 15 adolescentes), com duração de três horas semanais.

As Unidades da Fundação Casa são divididas em: Unidade de Internação Provisória (UIP); Unidade de Internação (UI); e Semiliberdade. O desenvolvimento das atividades culturais é bem específico entre elas. ${ }^{1}$

De acordo com Fortunato, Lambert e Araújo, na Fundação Casa,

\begin{abstract}
[...] a oficina cultural é a atividade de formação que ocorre com regularidade para mesma turma e com carga horária definida. Ela é ministrada e é de responsabilidade do arte-educador ou do profissional da área abordada, não possui duração determinada, mas exige-se planejamento e objetivos claros. As oficinas culturais devem apresentar resultados entre eles o envolvimento dos adolescentes em apresentações, exposições (FORTUNATO; LAMBERT; ARAÚJO, 2010, p.129)
\end{abstract}

A definição de "aula", ou "oficina", nos propõe rever que tipo de abordagem se aplica aos adolescentes em cumprimento de medida socioeducativa. O dicionarista Buarque de Holanda Ferreira define aula como: "explanação proferida por professor ou autoridade competente perante grupo de alunos"; e, oficina como "lugar onde se verificam grandes transformações" (FERREIRA, 1999, p.231) . Ele define oficina pedagógica como um conjunto de atividades laborativas orientadas por professores em que estão disponíveis diferentes tipos de equipamentos e materiais para o ensino ou aprendizagem, nas diversas áreas do desempenho profissional (Ibid., p.436).

De acordo com Libâneo, "a ideia mais comum que nos vem à mente quando se fala em aula é a de um professor expondo um tema perante uma classe silenciosa" (1994, p.177). As aulas de teatro, foco deste trabalho, fogem dessa descrição, por possuírem formato diferenciado.

1 Na UIP (Unidade de Internação Provisória) é necessário considerar a brevidade do atendimento e a rotatividade dos adolescentes, oferecendo linguagens apropriadas nesse período. Nas Unidades de Internação é possível trabalhar com continuidade nas oficinas, considerando que o período pode variar de 6 meses a 3 anos. As atividades de arte e cultura na Semiliberdade têm como objetivo a inclusão dos jovens em atividades culturais na comunidade (espetáculos, visitas, exposições entre outras). 
Para Coelho, de "uma oficina cultural não sai um produto ou obra cultural (uma peça de teatro, um filme, um livro), o objetivo é disseminar informações, para um público profissional ou amador, que levem à realização de obras culturais" (COELHO, 1999, p.281) .

A partir de minha experiência como arte-educadora, pude perceber que conciliar técnicas teatrais no ensino de teatro para jovens restritos de liberdade cria para o educador um desafio: apropriar-se de outros mecanismos para trabalhar a linguagem teatral sem que vivencie uma "frustrante passagem por um trabalho social".

A proposta de trabalhar em projetos sociais é, inicialmente, atraente e cria no educador muitas expectativas relacionadas ao desenvolvimento do traba1ho. Na prática, porém, o educador se depara com muitas frustrações, pois os alunos com quem passa a ter contato são oriundos de uma realidade que não lhe é familiar e que, muitas vezes, não tem propriedade para relacionarse. Além disso, há que se considerar o pouco reconhecimento salarial dessa categoria.

Nesse sentido, a própria definição de "oficina" sugere uma atividade laboratorial, ou oficina de teatro, como apresentado nesse trabalho. O termo "oficineiro", como explica Carvalho, "vem sendo utilizado no terceiro setor, para designar o ministrante de oficinas, independentemente de sua formação, sendo alguém que foi convidado ou contratado, temporariamente, para ensinar determinado assunto ou técnica" (2008, p.114).

No âmbito de projetos sociais, Penna considerou que a qualidade do ensino de arte, nas Ongs, não está necessariamente, relacionada à titulação. Entretanto, a não-qualificação dos profissionais que atuam em Ongs pode interferir na qualidade do trabalho.

\footnotetext{
Em relação ao educador que atua em projetos sociais, não há exigência legal de qualificação ou formação. Os projetos sociais convivem com profissionais que muitas vezes não priorizam o domínio do conhecimento da área em que se propõe a atuar. Além disso, não há um conteúdo comum a ser trabalhado, sob a justificativa de cada educador ter a liberdade de construir sua própria metodologia. (PENNA, 2011, p.46)
}

A meu ver, a exigência de qualificação e formação dos profissionais que atuam em projetos sociais deveria ser revista, considerando, como prioridade para contratação que a abordagem pedagógica de um profissional com formação é distinta da de um profissional que domina somente a linguagem artística da oficina que ministra. A demanda do público-alvo desses projetos exige muitos posicionamentos didáticos do educador, que, acredito, somente uma formação específica pode suprir. Na pesquisa "O ensino de artes em Ongs", Carvalho (2008) alerta que: 
[...] é grave a não exigência para formação superior dos educadores, visto que eles trabalharão com jovens que vivem em uma condição social precária que exigiria do "educador" posicionamentos políticos, éticos e estéticos alinhados ao da instituição e qualidades e aptidões pessoais que vão além das habilidades técnico profissionais (CARVALHO, 2008, p.108).

A nomenclatura utilizada para os profissionais que atuam nos Centros socioeducativos com as oficinas culturais é a de "arte-educador", para a qual encontrei algumas definições que caracterizam essa atividade profissional.

Os arte-educadores são artistas que entraram para a educação artística, nos três graus de ensino, e se tornaram, a partir de então, mais preocupados com os aspectos educacionais do ensino da arte do que os processos de ensino do desenho, da pintura da escultura, da gravura etc. (COELHO, 1999, p.56).

Ainda, de acordo com a Classificação Brasileira de Ocupação (BRASIL, 2002) o arte-educador está inserido na Família Ocupacional 5153, que agrupa os profissionais que trabalham para a atenção, defesa e proteção a pessoas em situação de risco e adolescentes em conflito com a lei. Não há definição específica para "arte-educador". A profissão aparece especificamente como sinônimo de "educador social", cuja atribuição é "assegurar direitos a crianças e adolescentes, abordando-as, sensibilizando-as, identificando suas necessidades e demandas de atividades e tratamento".

Em relação à experiência e formação necessárias para atuar nessa função, o acesso é livre, sem requisitos de escolaridade. Essa família ocupacional é composta pelos seguintes profissionais: educador social (arte-educador, educador de rua, educador social de rua, instrutor educacional, orientador socioeducativo).

De acordo com a CBO 5153 (BRASIL, 2002) o profissional desse grupo deverá, através de atividades, "sensibilizar os assistidos/ usuários / educandos resgatar a autoestima conscientizar sobre regras e normas, apontar alternativas, despertar aptidões, habilidades". Um aspecto considerável no campo de atuação desse profissional é que: "os trabalhadores dessa família ocupacional lidam diariamente com situações de risco assistindo indivíduos com alteração de comportamento, agressividade e em vulnerabilidade"(Ibid.).

A Gerência de Arte e Cultura da Fundação Casa propõe como uma das ações pedagógicas o desenvolvimento de palestras e workshops, que podem ser entendidos como uma "aula aberta" ou ainda como " aula show" cujo objetivo é mostrar, divulgar e sensibilizar o público (os adolescentes internos) acerca de uma determinada atividade ou linguagem. A atividade proposta deverá envolver todos os adolescentes. O workshop, geralmente, é uma atividade de curta duração, realizada no período de férias escolares dos adolescentes por um profissional convidado. Este termo é melhor explicado por Coelho: 
Workshop, termo de longa data utilizado na cultura anglo saxã (e no resto do mundo) para designar uma espécie de seminário originalmente conduzido por profissionais de destaque (atores e diretores conhecidos de teatro e cinema, literatura, etc.) visando intercâmbio de ideias e a demonstração de técnicas e habilidades desenvolvidas (COELHO, 1999, p.282).

Segundo Lopes (1989, p.23), o teatro pode ser uma ferramenta útil no sentido de se produzir uma prática transformadora: "teatro não é giz nem quadro negro. Ele é o jogo dramático que abre uma perspectiva de educação para quem faz e quem assiste".

É possível perceber que o teatro, nesse ambiente particular exerce sua força de agrupar pessoas encoraja-as a enfrentar novos desafios, acreditar em si mesmas e a pensar no outro, pois não ver o outro talvez tenha sido um dos fatores que fizeram com que muitos fossem parar nesse lugar (YAMAMOTO, 2009, p.103).

Nessa perspectiva, a Superintendência pedagógica da Fundação Casa acredita que a área de Arte e Cultura contribuirá:

[...] substancialmente com o plano individual de atendimento (PIA) tanto no que diz respeito ao desenvolvimento do próprio adolescente construção de valores, posturas, atitudes, como também aos educadores e técnicos, pois é um instrumento importantíssimo de conhecimento e aproximação do adolescente (FORTUNATO; LAMBERT; ARAÚJO, 2010, p.121).

O resultado final das oficinas culturais é proposto no "compartilhamento simbólico". Pressupõe-se que compartilhamento ${ }^{2}$ são os resultados alcançados nas oficinas, e que este compartilhamento deverá ser realizado através de apresentações de espetáculos, exposições de obra de arte, entre outras atividades realizadas pelos adolescentes através do trabalho com oficineiros.

O compartilhamento simbólico traz a possibilidade de explorar o espaço físico dos Centros, ressignificando-o, ao transformar o pátio, que se torna um ambiente rotineiro ao longo da internação em um "espaço para apresentação de espetáculos".

Por isso, na arte-educação o que importa não é o produto final obtido, não é a produção de boas obras de arte. Antes a atenção deve recair sobre o processo de criação. O processo pelo qual o educando deve elaborar seus próprios sentidos em relação ao mundo a sua volta. A finalidade da arte-educação deve ser sem-

2 A ação pedagógica "compartilhamento simbólico" é um segmento de trabalho que compõe o Projeto Pedagógico do Projeto Arte para todos. 
pre o desenvolvimento de uma consciência estética (DUARTE JÙNIOR, 1994, p.73).

Olga Reverbel destaca que o objetivo do teatro na "escola" (considerando nessa pesquisa o espaço de um Centro socioeducativo) "não é ter um aluno-ator, um aluno compositor, mas sim dar oportunidades a cada um de descobrir o mundo, a si próprio e a importância da arte na vida humana" (1997, p.22).

A proposta de atividades de Arte e Cultura nos Centros da Fundação Casa está assim delineada: o adolescente precisa ter acesso a manifestações artísticas que ele não conhece (música, artes visuais, dança, teatro), aprendendo através da experiência estética, a respeitar a produção dos colegas, receber e elaborar críticas. A aproximação das manifestações artísticas de diversas culturas permite ao adolescente ampliar o olhar para o mundo que o cerca.

Para Volpi (2002, p.23) "o papel do desenvolvimento das atividades é educar para o exercício da cidadania e não meramente ocupar o tempo e gastar a energia dos internos." O autor acredita que a realização de atividades lúdicas, culturais, e esportivas deve ser consideradas como fundamentais no processo educacional e não um mero instrumento de preenchimento do tempo ocioso.

\section{Métodos}

De acordo com Godoi, "O encontro tem uma boa dose de acaso, mas nunca é de todo previsível" (2006, p.319) . A definição dos sujeitos desta pesquisa foi um marco de transformações do trabalho, que se deram a partir das escolhas metodológicas que feitas, inicialmente pela entrevista semiestruturada com adolescentes em conflito com a lei, egressos da Fundação Casa, em um contexto de reintegração à sociedade.

As entrevistas realizadas foram gravadas em áudio. Segundo Queiroz:

\begin{abstract}
[...] uma vez que a voz do entrevistado, suas entonações, suas pausas, seu vaivém no que contava, constituíam outros tantos dados preciosos para o estudo, é preciso conservar com maior precisão a linguagem do narrador, suas pausas que podiam ser simbolicamente transformadas em sinais convencionais. (QUEIROZ, 1988, p.16).
\end{abstract}

Na primeira etapa da pesquisa assumi o risco de entrevistar adolescentes que passaram pela Fundação Casa, em seu próprio habitat, e não dentro da instituição deslocando o espaço da pesquisa para "bocas", esquinas e praças. Tinha consciência que poderia haver a recusa por parte dos adolescentes. Encontrei jovens sobre os quais eu pouco sabia fora das "muralhas" da insti- 
tuição. Não sabia sobre a sua construção de vida em liberdade após terem cumprido uma medida socioeducativa. ${ }^{3}$

Outro fator a ser considerado é que os jovens têm a minha imagem vinculada à figura de uma funcionária da Fundação Casa, instituição com a qual eles não querem contato. Minha imagem estava associada à de um delator, que poderia denunciá-los por uma conduta ilegal. Assim, realizei a pesquisa de campo no final do meu primeiro ano de pesquisa, já desligada do "Projeto Arte para todos" ${ }^{\prime 4}$ como arte-educadora. As entrevistas foram realizadas com jovens egressos.

Diante das circunstâncias em que encontrei os jovens, alguns no exercício do tráfico de drogas, em periferias de Ribeirão Preto - SP, este fato impossibilitou que o procedimento formal de entrevistas fosse realizado. Com a indisponibilidade do entrevistado, não foi possível marcar um local adequado para dialogar tranquilamente sem qualquer tipo de interferência do meio. Nessas condições, frente à dificuldade de estabelecer um diálogo tranquilo, a recusa dos jovens foi marcante. Antes do "sim" de oito jovens que aceitaram participar das entrevistas ouvi muitos "nãos" como resposta.

\begin{abstract}
Existe uma perda entre o vivido e o relatado, mas o encontro entre o pesquisador e a pessoa que participa do estudo pode ser rico em significados, desde que a relação seja pautada na confiança e no respeito e também na valorização do que está sendo descrito pela pessoa. Em alguns casos, conseguir a confiança no primeiro encontro é difícil (GODOI, 2006, p.295).
\end{abstract}

Optar por encontrar os jovens da Fundação Casa após a Internação, utilizando, como abordagem, a técnica de entrevistas, não favoreceu coletar os dados necessários para a realização da proposta inicial da pesquisa. Entretanto, os jovens que falaram comigo nas esquinas dos bairros visitados me trataram com muito respeito, colaboraram com a minha busca, indicando-me lugares, apresentando outros garotos, e autorizando a gravação da conversa, como "lembrança" do período de privação de liberdade. Continuei sendo tratada como "senhora" ou "dona".

No decorrer do processo de entrevistas, consegui conversar com oito jovens, porém não estavam diretamente envolvidos na oficina de Teatro. Dessa

\footnotetext{
3 Para realizar pesquisa de campo no espaço físico da Fundação Casa é necessário realizar alguns protocolos com o Centro de Pesquisa e Documentação Escola de Formação e Capacitação Profissional Fundação Casa SP, de acordo com a Portaria Normativa 155/2008. Obtive indeferimento, pois a avaliação da proposta considerou que a pesquisa exigia muitas horas de trabalho com os adolescentes, o que interferiria na rotina semanal dos Centros, que já possui em seu cronograma pedagógico um grande número de atividades das quais os jovens participam cotidianamente, não havendo, dessa forma, interesse institucional para a realização da pesquisa no momento solicitado.

4 O Projeto "Arte Para Todos" é um convênio da ONG GADA (Grupo de Amparo ao Doente de AIDS) com a Fundação Casa, para prestação de serviço, referente a oficinas culturais em Centros socioeducativos, localizados na região Norte do estado de São Paulo)
} 
forma, não poderiam contribuir com lembranças do "fazer teatral" no período de internação nos Centros, como havia sido a problematização inicial da pesquisa, o que impossibilitou a utilização da análise dos dados de forma profícua.

Dos oito jovens entrevistados, somente três passaram pela oficina de teatro. Por isso, optei por mantê-los nesta pesquisa, utilizando suas narrativas em relação ao que vivenciaram nas oficinas de Teatro no período em que cumpriram medida socioeducativa na Fundação Casa como material de apoio dando subsídios aos relatos dos arte-educadores.

Dessa forma, os três arte-educadores de teatro entrevistados passaram a ser os sujeitos desta discussão. Essa escolha foi determinante para o trabalho, pois a investigação passou a ter a "realidade e o ponto de vista de alguém de "dentro" do estudo de caso, e não de um ponto de vista externo" (YIN, 2005, p.122).

Para viabilizar a pesquisa, as entrevistas com os arte-educadores e os adolescentes egressos foram agrupadas nas seguintes categorias de análise: 1conflitos para o desenvolvimento das aulas de teatro; 2- como pensar uma pedagogia teatral contribuindo na formação de jovens em cumprimento de medida socioeducativa; e, 3 - procedimentos de trabalho utilizados nas oficinas de teatro.

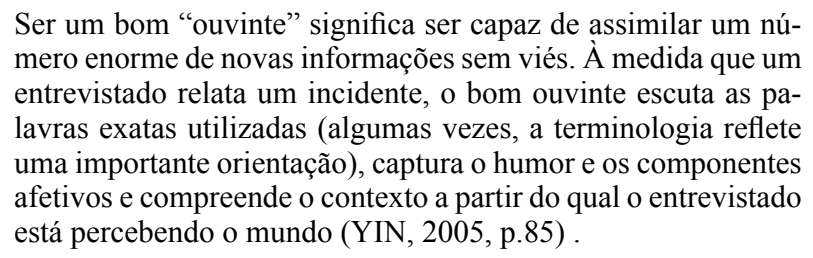

Dessa forma, passou-se a adotar como metodologia desta pesquisa um estudo de caso descritivo, com um recorte específico, as oficinas de Teatro realizadas no "Projeto Arte para todos" em Ribeirão Preto SP.

\footnotetext{
O estudo de caso conta com muitas das técnicas utilizadas pelas pesquisas históricas, mas acrescentam duas fontes de evidência que usualmente não são incluídas no repertório de um historiador a observação direta dos acontecimentos que estão sendo estudados e entrevistas das pessoas neles envolvidos (YIN, 2005, p.26).
}

Para Yin, o pesquisador que escolhe realizar um estudo de caso deve ser "adaptável e flexível, de forma que as situações recentemente encontradas possam ser vistas como oportunidades, não ameaças.” (Ibid., p. 83) 


\section{O arte-educador}

Adotando a minha experiência como arte-educadora na Fundação Casa como ponto de partida, entrei em contato com outros educadores com o objetivo de entrevista-los e registrar suas narrativas referentes à experiência em ministrar oficinas de teatro para jovens em cumprimento de medida socioeducativa de internação, compreendendo os principais conflitos de trabalhar arte-educação nesse espaço, e como definir uma metodologia de teatro que atenda às necessidades pedagógicas dos Centros.

Assim, foram analisadas as narrativas de três arte-educadores professores de teatro do Projeto "Arte para Todos". O arte-educador 1 é graduado em Artes Cênicas, especialista em arte-educação, e trabalha há dois anos na Fundação Casa. Assim ele descreve a sua experiência:

Quando entrei na Casa, tinha muito medo pelo contexto de ser a Fundação Casa, tinha um medo pessoal em relação aos meninos, mas assim posso dizer que a Casa, foi o melhor lugar que eu dei aula até hoje.

Como professor de Teatro para adolescentes em conflito com a lei, o arte-educador 1 considera que:

(...) Eu penso no teatro, não como um fim, não é um espetáculo que importa então a gente aprende, e aí na verdade passa a ver o teatro como um meio pedagógico para trazer algo para esses meninos".

(...) utilizar o teatro para acrescentar para eles como pessoa, para eles crescerem como seres humanos, e se algum despertar para a coisa artística é algo mais.

$\mathrm{O}$ arte-educador 2 é graduado em Pedagogia, também trabalha como ator, e atua há dois anos na Fundação Casa como arte-educador. Ele define a experiência do trabalho com teatro com jovens internos como:

Uma experiência que te prepara, acredito, que para muita coisa. É uma experiência que te faz feliz, que te faz triste. Você consegue obter pequenos sucessos, mas também muitas frustrações. Trabalhar em um espaço, com arte-educação, em um espaço como a Fundação Casa, é algo muito difícil. É como se você tivesse realmente remando contra uma maré.

O referido arte-educador acredita que o teatro, para adolescentes em conflito com a lei, poderá ser: 
Um instrumento para que ele desenvolva essa parte da comunicação, para que ele consiga expressar melhor, para que ele consiga se colocar em público melhor, que isso vai fazer a diferença na vida dele profissionalmente, que isso vai fazer uma diferença na vida pessoal nas relações com os amigos. Isso na minha visão é colocar o trabalho com arte de uma forma pragmática de como isso serve no dia- a- dia do adolescente.

O arte-educador 3 possui curso técnico em Artes Cênicas, é graduado em Pedagogia e trabalhou durante dois anos como professor de Teatro na Fundação Casa. Segundo este educador, no período que trabalhou teatro nos Centros concluiu que:

Pude, de forma profunda e única, quebrar paradigmas, romper com barreiras sociais e culturais, ver o mundo de uma forma muito real. Colocar em prática ideias, visões, soluções e problemas antes vistos com olhar medíocre.

Para este arte-educador, o principal objetivo como professor de teatro nos Centros era:

\begin{abstract}
(...) Transpor as próprias barreiras impostas pela Fundação Casa, conseguir trabalhar a vivência do ser humano em conflito com a lei de forma limpa e pura, podendo utilizar a realidade de cada interno como ferramenta de trabalho.
\end{abstract}

Trabalhar com teatro no espaço de um centro socioeducativo, com jovens inicialmente resistentes a essa proposta apresenta ao arte-educador um caminho muitas vezes conflituoso, que oscila entre poucos resultados e muitas frustrações. Enfrentar as dificuldades de abordagem pedagógica e problemas institucionais e permanecer atuando profissionalmente nesse espaço é uma atitude louvável dos arte-educadores, por garantirem aos internos o acesso a uma vivência teatral que pode ser restrita à passagem do adolescente pela Fundação Casa.

Os arte-educadores entrevistados possuem algo em comum: formação técnica ou acadêmica em teatro, apesar de esta formação não ser uma exigência determinante para a contratação. Além disso, atuam em Centros socioeducativos há mais de um ano, no projeto "Arte para Todos" da Ong GADA, o que permite um contato maior com os adolescentes no desenvolvimento de "vivências teatrais" nos Centros.

\title{
O que vivenciaram os jovens egressos nos Centros?
}

Os jovens egressos entrevistados são três ex-alunos de teatro que passaram pelos Centros da Fundação Casa em Ribeirão Preto (SP) no período de 
outubro de 2009 à janeiro de 2012. Esses jovens narram algumas atividades que vivenciaram na oficina de teatro no período em que cumpriram medida socioeducativa. Outras narrativas aqui exploradas são registros das oficinas de teatro por mim ministradas, as quais foram incorporadas ao trabalho. Cabe ressaltar que foram criados nomes fictícios para preservar a identidade dos entrevistados.

Bracinho: "O menino que roubava por roubar", adolescente de 19 anos, cumpriu internação na Fundação Casa por um ano e meio. Achava que com a vida que levava daria um futuro melhor para a sua mãe e seus irmãos, e que, mesmo passando por dificuldades, no período em que ele esteve internado, não deixava de visitá-lo. Assim, decidiu trabalhar e ajudá-la. Segundo o jovem, o "mundo do crime" só deixou sequelas. O jovem afirma que se envolveu com roubo, e o período de internação foi um momento de reflexão porque, internado e fazendo várias atividades, conseguiu refletir. A internação, segundo ele, permitiu, "ver o que era bom", e afirma que "resolvi mudar, porque não me levou a nada fazer isso daí, dona!"

Ele cita os motivos que o conduziram a cometer um ato infracional:

É de momento. Às vezes você quer se iludir, sei lá, achando que é uma coisa. Você começa a trabalhar e vê que o moleque tem uma coisa maior que a sua, aí você vê aquilo lá também, ganhar dinheiro fácil, você acaba indo. Aí você vai se envolvendo cada vez mais, você não consegue parar, você começa a vender droga, depois passa por uma parte maior gerenciando, depois você vai querer roubar. Aí acaba acontecendo as coisas.

No decorrer de um ano e meio de internação o referido jovem participou das oficinas culturais de teatro e na percussão.

O que eu tenho de memória de lá (pausa, sorriso) tem coisas boas, porque lá dentro eu pude conhecer várias pessoas do gênero bom assim, que se comunica, aprendi bastante a se comunicar com as pessoas na dança de rua, no teatro. Teve um tempo que eu fiquei na capoeira, isso aí tudo ajudou bastante, porque eu não conseguia me expressar com as pessoas, eu sentia vergonha de falar de ler na frente dos outros eu tinha vergonha. Lá eu consegui fazer tudo isso aí, aí foi bom para mim.

Questionado sobre a continuidade de sua participação em oficinas de teatro fora dos centros reforça: "Às vezes eu até penso, duro é o tempo, onde eu trabalho não tem tempo para fazer isso aí".

Moleque Progresso - "O menino que aprendeu a pensar duas vezes", adolescente de 19 anos, cumpriu duas internações na Fundação Casa, uma de nove meses e a outra de sete meses. Acredita que entrou no "mundo do crime" 
porque sua família passava por muita necessidade. O período de internação o ensinou a pensar duas vezes, embora ele reconheça que é difícil sair desse "mundo" depois que entra nele.

Para o jovem, o que o levou a cometer um ato infracional foi "necessidade de ter as coisas né (pausa longa) isso ai não gosto de falar não, mexe com a pessoa" (pausa).

Pensar nas coisas que você faz né, porque tudo que você faz tem que arcar com as consequências, né, tem que pensar mais, tem que pensar duas vezes antes de fazer os bagulho.

Durante a passagem pelos Centros o jovem participou da oficina de capoeira, dança de rua e do teatro, com o qual mais se identificou: "Era o teatro dona! Tinha saidinha, a gente saía para outros módulos". O jovem apresenta, em sua narrativa, de que forma acredita que o teatro contribui para sua experiência de vida:

Ah, mano, aprendeu, né mano, que todo mundo tem um talento, né mano, correr atrás, cada um tem uma vocação né, e aprender um pouco da arte, e é divertido também.

Pedrinha - "O menino que teve espelhos", adolescente, 17 anos, quatro internações na Fundação Casa. A primeira internação, com apenas 13 anos, segundo ele, por tráfico de entorpecentes, porte de armas e tentativa de homicídio. Acredita que o que levou ao "mundo do crime" foi a falta de referência familiar, pois afirma que todos os membros da sua família são "envolvidos", e desde pequeno ele teve "espelhos".

Ah! mudança foi o seguinte, que nóis num sai da vida. Quanto mais nóis entra lá dentro, nóis vai fica pior ainda, porque lá num é uma faculdade pi cê melhorar. Lá é a faculdade do crime memo, lá o bagulho é louco!

Segundo ele, participar das atividades de arte e cultura na Fundação Casa foi um processo que: "ah, aprender eu não aprendi, não né dona Fernanda! Eu vou falar a verdade pi cê."

A partir das entrevistas realizadas com adolescentes que passaram pela oficina de teatro, constatei que é muito difícil para o adolescente dar continuidade às oficinas culturais após a passagem pela Fundação Casa, pois é como se ele voltasse para aquela realidade. Sem o apoio institucional, ele se depara com a reconstrução da sua vida em liberdade, e isso inclui trabalhar e continuar estudando. Devido à condição social do adolescente, ele prioriza o trabalho e abandona os estudos. 


\section{Conclusões}

A partir da minha experiência como arte-educadora de teatro em Centros socioeducativos, entrei em contato com outros educadores para tentar compreender o valor pedagógico das atividades artísticas por eles desenvolvidas e qual o espaço ocupado pela arte-educação no trabalho com jovens em conflito com a lei. Busquei compreender, por meio de seus relatos, as angústias, as impressões, as dificuldades de conduzir a arte-educação em um espaço que ainda é avesso, na prática, à essa proposta

Pude ainda perceber que o conflito inicial está relacionado ao próprio espaço. O Centro socioeducativo é um ambiente educacional, mas ao mesmo tempo é caracterizado pela "privação de liberdade" e por todo um sistema disciplinador que o compõe, onde se encontram jovens, separados da sociedade por um período e que, cotidianamente, levam uma vida administrada por horários e atividades pedagógicas obrigatórias. Os Centros socioeducativos têm, portanto, como objetivo, ressocializar o adolescente para que ele não reincida na prática de atos infracionais.

Pode-se perceber, a partir do relato dos conflitos, que os arte-educadores vivenciam que, verdadeiramente, não há uma compreensão das contribuições pedagógicas de vivências proporcionadas pela arte. Isto, em certa medida, foi identificado pelas contradições entre o que acontece na prática e o que propõe o projeto pedagógico no que se refere à Arte e Cultura.

Esse dado, identificado nas situações narradas pelos arte-educadores, coloca portanto, em questão o objetivo pedagógico das atividades de Arte e Cultura em centros socioeducativos. Preencher uma matriz pedagógica, preencher o tempo e livrar os internos cheios de energia do tempo ocioso?

Como resultado final desta pesquisa, é possível dizer que o impacto das oficinas de teatro na vida dos adolescentes é inconclusivo, embora tenha havido indícios de que as práticas estéticas e artísticas possibilitadas pela arte teatral tenha produzido nos sujeitos elementos do discurso que reforçam o que os estudos do campo da arte-educação - sobretudo na pedagogia do teatro - vem apontando, ou seja, que o trabalho do arte-educador com jovens em conflito com a lei, cria subsídios para que a arte resignifique esse espaço, embora os processos teatrais vivenciados pelos jovens sejam intermitentes.

\section{Referências bibliográficas}

BAUER, Martin W. Pesquisa qualitativa com texto imagem e som: um manual prático. In: BAUER, Martin W.; GASKELL, George (Edit.). Tradução: Pedrinho A. Guareschi, 6 ed. Petrópolis, RJ: Vozes, 2007.

BRASIL (Presidência da República). Lei n. 8069 de 13 de julho de 1990. Dispõe sobre o Estatuto da Criança e do Adolescente e dá outras providências. Disponível em: $<$ http://www.planalto. gov.br/ccivil_03/leis/18069.htm> Acesso em: 26 out. 2013. 
. (Ministério do Trabalho e Emprego). Portaria 397 de 09 de outubro de 2002. Aprova a Classificação Brasileira de Ocupações - CBO/2002, para uso em todo território nacional e autoriza a sua publicação. Disponível em: <http://www.mtecbo.gov.br/cbosite/pages/legislacao. jsf> Acesso em: 26 out. 2013.

. (Presidência da República. Secretaria Especial dos Direitos Humanos. Conselho Nacional dos Direitos da Criança e do Adolescente.). Sistema Nacional De Atendimento Socioeducativo -SINASE/ Secretaria Especial dos Direitos Humanos - Brasília-DF: CONANDA, 2006.

CARVALHO, Lívia Marques. O ensino de artes em ONGS. São Paulo: Cortez, 2008.

COELHO, Teixeira. Dicionário de Política Cultural. São Paulo: Iluminuras, 1999.

COSTA, Antônio Carlos Gomes da. Socioeducação: estrutura e funcionamento da comunidade educativa. Brasília: Secretaria Especial de Direitos Humanos, 2006.

DESGRANGES, Flávio. A Pedagogia do teatro: preparação e dialogismo. 2 ed. São Paulo: Editora Hucitec: Edições Mandacaru, 2010. . A Pedagogia do espectador. São Paulo: Hucitec, 2003 (Teatro 46).

DUARTE JUNIOR. João Francisco. Fundamentos estéticos da educação. Campinas, SP: Papipurs, 1988.

. Porque arte-educação? 7 ed. Campinas: Papirus, 1994, (Coleção Alegre)

FORTUNATO, Marisa; LAMBERT, Ana Regina Lambert; ARAÚJO, Wellington do Carmo Medeiros de. Superintendência Pedagógica Educação e medida socioeducativa: conceitos, diretrizes e procedimentos. São Paulo, 2010.

FUNDAÇÃO CASA. Portal Eletrônico da Fundação Centro de Atendimento Socioeducativo ao Adolescente - Fundação CASA-SP. Disponível em: <http://www.fundacaocasa.sp.gov.br/ index.html> Acesso em: 20 set. 2013.

GODOI, Christiane Kleinübing et al. (Org.). Pesquisa qualitativa em estudos organizacionais: paradigmas, estratégias e métodos. São Paulo: Saraiva, 2006.

GRACIANI, Maria Stela Santos. A Pedagogia Social no Trabalho com Crianças e Adolescentes em Situação de rua. In: SOUZA, NETO, João Clemente de; SILVA Roberto da; MOURA, Rogério Adolfo de (Org). Pedagogia Social. 2 ed. São Paulo SP: Expressão \& Arte, 2011.

KOUDELA, Ingrid Dormien. Jogos Teatrais. 7a. ed., São Paulo: Perspectiva, 2009.

LIBÂNEO, José Carlos: Didática. São Paulo: Cortez, 1997.

LOPES, Joana. Pega Teatro. Campinas, SP: Papirus, 1989.

PENNA, Violeta Vaz . Oficinas de Dança em Projetos Socioculturais: experiências estéticas e educativas de jovens e professores. Belo Horizonte, 2011, 177fls. Dissertação (Mestrado em Educação). Universidade do Estado de Minas Gerais, Belo Horizonte, 2011. 
SILVA, F. R. L. Sentidos atribuídos à oficina de teatro em centros socioeducativos.

QUEIROZ, Maria Isaura Pereira. Relatos orais do "indizível" ao "dizível”. In: VON SIMSON Olga de Morais. Experimentos com histórias de vida. São Paulo: Vértice, Editora Revista dos Tribunais, 1988.

REVERBEL, Olga. Um caminho do Teatro na Escola. São Paulo: Spicione, 1997.

SEVERINO, Antônio Joaquim. Metodologia do Trabalho Científico. 23 ed., São Paulo: Cortez, 2007.

SOUZA, Roberta Vanessa P. Aranha. O ensino formal da Fundação CASA e a Interdisciplinaridade como busca de sentido para um novo Currículo. São Paulo, 2011, 125 fls. Dissertação (Mestrado em Educação: Currículo). Pontifícia Universidade Católica de São Paulo, São Paulo, 2011.

SOUZA NETO, João Clemente de; SILVA Roberto da; MOURA, Rogério Adolfo de (Orgs.). Pedagogia Social. 2 ed. São Paulo: Expressão \& Arte, 2011

SPOLIN,Viola. Improvisação para o teatro. São Paulo: Editora Perspectiva S.A. , 2001.

YAMOTO, Karina Ribeiro. Riso e Temor: trajetórias teatrais no Internato de Pirituba/Fundação Casa. São Paulo, 2009, 172 fls. Dissertação (Mestrado em Artes Cênicas da Escola de Comunicações e Artes) Universidade de São Paulo, São Paulo, 2009.

YIN, Robert K. Estudo de Caso: planejamento e métodos trad. 3 ed. Porto Alegre: Bookman, 2005.

Submissão em: 10/09/2013

Revisão em: 01/03/2014

Aceite em: 19/03/2014

Fernanda Roberta Lemos Silva é atriz, educadora social, arte educadora, Bacharel em Artes Cênicas pelo Centro Universitário Barão de Mauá Ribeirão Preto SP. Mestre em Educação Linguagem Arte e Conhecimento grupo de Pesquisa OLHO (Laboratório de Estudos Audiovisuais), Universidade Estadual de Campinas. Endereço: Rua Professor Bernadino Victório Previatello, n 220. Parque dos Servidores, Ribeirão Preto/SP. CEP 14094 -238. E-mail: nandateatro@yahoo.com.br 